\title{
INVENTÁRIO E DIAGNÓSTICO DA ARBORIZAÇÃO URBANA VIÁRIA DE RIO BRANCO,
} AC.

Ary Vieira de Paiva ${ }^{1}$, Anderson Bryan Miranda Lima ${ }^{2}$, Anelena Carvalho ${ }^{2}$, Arnaldo M. Junior ${ }^{2}$, Aruan Gomes², Cassia S. Melo², Clarice O. Farias², Cledson Reis², Clivia Bezerra², Elias A. S. Junior ${ }^{2}$, Erivania Macedo ${ }^{2}$, Erivelton S. Lima ${ }^{2}$, Fabricia Sobrinho², Francelino M. Silva², Jose Caldio Bonfim², Lino S. Junior ${ }^{2}$, Mayara Correa ${ }^{2}$, Marcio L. Dumont ${ }^{2}$, Marcos A. Isaac Junior $^{2}$, Nara V. Pantoja ${ }^{2}$, Raimundo M. Davila ${ }^{2}$, Ranieldo Gabriel ${ }^{2}$, Renato A. Silva ${ }^{2}$, Renato M. Cunha ${ }^{2}$, Renato S. Oliveira ${ }^{2}$, Robelson Dias $^{2}$, Sara P. Nicheli ${ }^{2}$, Solaine Costa ${ }^{2}$, Tatianne C. Souza ${ }^{2}$, Tersio F. Pereira ${ }^{2}$, Zairon Castelo $^{2}$, Zeina S. Ferrari' (recebido em 02.04.2009 e aceito para publicação em 23.03.2010)

\section{RESUMO}

O presente trabalho foi desenvolvido dentro do perímetro urbano da cidade de Rio BrancoAC, localizada entre as coordenadas geográficas de 9 ${ }^{\circ} 8^{\prime} 29^{\prime \prime}$ de latitude sul e 67²4'36" de longitude oeste. Teve como objetivo geral o levantamento e diagnóstico da arborização viária. A metodologia estatística utilizada foi definida tomando-se como unidade amostral o quarteirão. Encontrou-se pouquíssimos espécimes nas calçadas dos quarteirões amostrados, totalizando 292 indivíduos distribuídos por 39 espécies, sendo 11 nativas e 28 exóticas. A média por quarteirão foi de 1,83 árvores, e por quilômetro de calçada foi de 4,57 árvores. Concluiu-se que o número de árvores existentes nas calçadas foi muito pequeno, tendo-se como referência 100 árvores por quilômetro de calçada como ideal. A maioria das espécies encontrada era exótica $(78,57 \%)$, a despeito da cidade encontrar-se numa região com uma das maiores diversidades de espécies arbóreas do planeta. Quanto ao estado físico, a copa normal foi predominante, exceto na região central. As recomendações indicadas foram primeiramente de se elaborar um plano de arborização urbana para o município, contendo referências técnicas para escolha das espécies, técnicas de manejo e programa de educação ambiental.

Palavras-chaves: Arborização urbana, inventário, diagnóstico, Rio Branco

\footnotetext{
${ }^{1}$. Eng ${ }^{\circ}$. Agr ${ }^{\circ}$. Dr. Professor da Universidade Federal do Acre - UFAC, Centro de Ciências Biológicas e da Natureza - CCBN. Rod. BR 364, km 4, Distrito Industrial, CEP: 69.915-900 - Rio Branco, AC. aryvieira1@hotmail.com;

2 .Graduandos do curso de Engenharia Florestal da UFAC.
} 


\title{
INVENTORY AND DIAGNOSIS OF URBAN FOREST OF RIO BRANCO, AC.
}

\begin{abstract}
This work was developed within the perimeter of the city of Rio Branco-AC, located between the geographic coordinates of $9^{\circ} 58^{\prime 2} 29^{\prime \prime}$ south latitude and $67^{\circ} 48^{\prime} 36^{\prime \prime}$ west longitude. The general aim was the research and diagnosis of sidewalk afforestation. The statistical methodology used was defined using as the sampling unit block. There were found very few specimens in the sidewalks of the blocks sampled, totaling 292 individuals in 39 species, 11 native and 28 exotic. The average per block was 1.83 trees, and kilometers of sidewalk trees was 4.57. It was concluded that the number of existing trees on sidewalks was very low, taking as reference 100 trees per $\mathrm{km}$ of sidewalk as ideal. Most exotic species was found (78.57\%), despite the city lying in a region with one of the greatest diversity of tree species on the planet. The physical state, the crown was predominantly normal, except in the central region. The recommendations made were first to develop a plan of urban landscaping for the city, with references to technical choice of species, management techniques and environmental education program.
\end{abstract}

Key-word: Inventory, Diagnosis, Urban Forest, Rio Branco

\section{INTRODUÇÂO}

O trabalho fez parte da disciplina de Arborização Urbana e Paisagismo, oferecida no curso de Engenharia Florestal da Universidade Federal do Acre - UFAC, quando os alunos tiveram que desenvolver projeto supervisionado de inventário e diagnóstico da arborização urbana encontrada nas vias públicas do município.

As primeiras cidades foram concebidas sem planejamento urbano para uso e ocupação do solo, surgindo posteriormente este conjunto de medidas para racionalizar e disciplinar a implantação de edificações, vias públicas e infra-estrutura urbana (MILLER, 1996). Assim sendo, a vegetação encontrava pouco ou nenhum espaço nestes ambientes. Ainda assistimos atualmente reflexos desta forma aleatória na formação e crescimento da maioria de nossas cidades, mesmo as localizadas nas regiões mais desenvolvidas, como no sul e sudeste brasileiros. No Brasil ainda os projetos de áreas verdes e vegetação viária são complementares aos das edificações (MACEDO,1999), vias públicas e outros equipamentos de infra-estrutura, ficando relegado a um segundo plano, apesar dos grandes avanços técnicos desenvolvidos na área e da sensibilização da população quanto à necessidade de um ambiente urbano com qualidade. 
Os efeitos benéficos da arborização para o conforto ambiental urbano são indiscutíveis segundo Miller (1996) e Milano (1987) dentre outros. Em cidades com temperaturas médias diárias acima do considerado ideal para o ser humano, estes efeitos poderão ser muito mais perceptíveis, podendo melhorar substancialmente a qualidade de vida da população, como no caso, as cidades da região norte do Brasil.

O inventário é o primeiro passo para se conhecer as características do sítio urbano, tanto nos aspectos físicos quanto biológicos, para embasar o planejamento da arborização a ser implantada, bem como nortear projetos de pesquisa visando identificação de novas espécies aptas ao ambiente urbano e técnicas de manejo da arborização (MILLER, 1996).

O segundo passo é o de oferecer os dados levantados ao poder público municipal contribuindo assim para a elaboração de planos e projetos do verde público urbano, tanto em sua implantação, quanto na sua manutenção e manejo, na perspectiva de uma cidade sustentável.

No Brasil, as técnicas de inventário têm avançado bastante, sendo utilizadas atualmente em várias cidades, de diversas regiões (ANDRADE, 2002; COSTA, 1993; COUTO e RACHID, 1999; COUTO, 2006; DANTAS E SOUZA, 2004; MENEGHETTI, 2003; MILANO, 1987; SILVA, 2005; SILVA, 2007).

Levantando a ocorrência de espécies florestais no Acre, tendo como base inventários florestais e levantamentos florísticos já realizados, Araújo e Silva (2000) encontraram 786 espécies nativas, mas este número pode ultrapassar 3.000 espécies, já que somente parte das florestas do Estado foi inventariada, apontando o grande potencial de espécies para uso no meio urbano.

Objetivou-se o levantamento de dados sobre a arborização urbana viária de Rio Branco-AC, a elaboração de diagnóstico e recomendações para sua gestão adequada.

\section{METODOLOGIA}

A pesquisa foi desenvolvida dentro do perímetro urbano da cidade de Rio BrancoAC, localizada entre as coordenadas geográficas de 9 ${ }^{\circ} 58^{\prime} 29^{\prime \prime}$ de latitude sul e 6748'36" de longitude oeste , a uma altitude de $152,5 \mathrm{~m}$, com temperaturas médias mensais entre $21 \mathrm{e}$ $33^{\circ} \mathrm{C}$, sendo a média em torno de $25^{\circ} \mathrm{C}$, precipitação média de $1.918,5 \mathrm{~mm}$ por ano, com um período chuvoso (novembro a abril) e um período de seca (maio a outubro), possuindo área territorial de $9.233 \mathrm{~km}^{2}$ e população total aproximada de 280.000 habitantes (ACRE, 2006).

Rio Branco encontra-se na província geomorfológica da Depressão do Rio Branco, com um relevo muito dissecado, com topos convexos e densidade de drenagem muito alta, 
apresentando declives medianos na parte centro-norte, diminuindo para sul, onde se torna suave ondulado. Ocorrem luvissolos, argissolos e plintossolos (ACRE, 2006).

A partir de uma planta em CAD da malha urbana, definiu-se 10 áreas, correspondendo a 22 bairros, totalizando 639 quarteirões, sendo amostrados aleatoriamente 65, conforme Figura 1, de onde foram coletados os dados pelos alunos da disciplina de Arborização Urbana e Paisagismo do curso de Engenharia Florestal da UFAC.

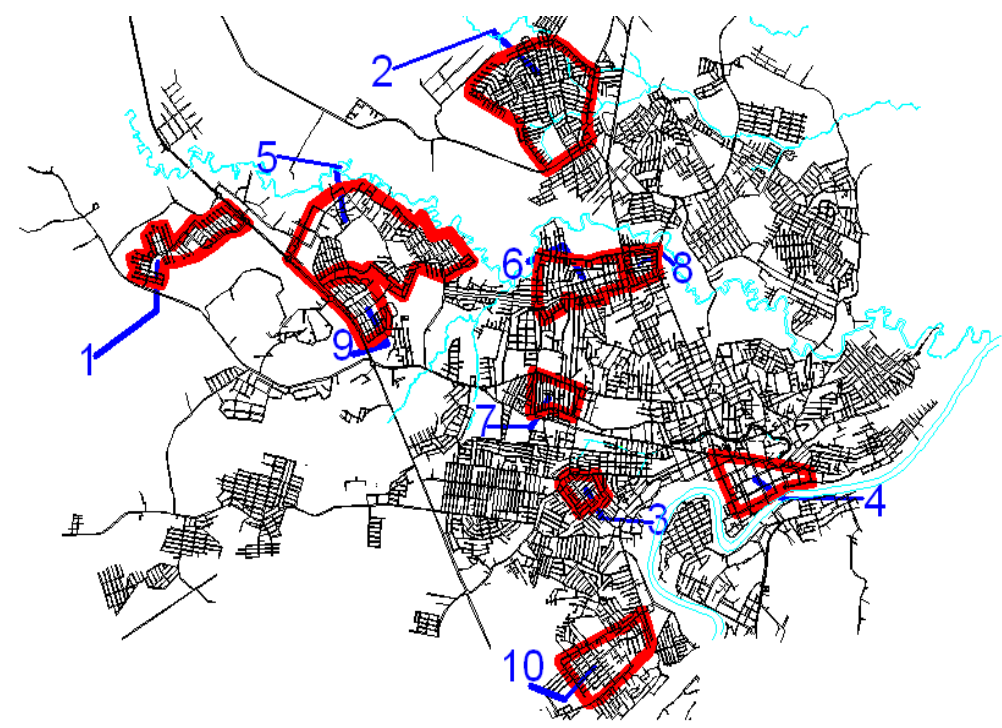

FIGURA 1. Mapa em CAD da cidade de Rio Branco, exibindo as dez áreas utilizadas no inventário da arborização urbana. 1- Conj. Universitário; 2 - Tancredo Neves; 3 - Floresta; 4 Centro; 5 - Rui Lino, Distrito Industrial, Mocinha; 6 - Conquista, Santa Quitéria, Ivonete; 7 Estação Experimental; 8 -Procom-Solar; 9 - Tucumã; 10 - Boa União e Glória.

A metodologia estatística utilizada foi definida tomando-se como unidade amostral o quarteirão (amostragem casual simples), recomendada por Couto e Rachid (1999), demonstrando ser a mais adequada e prática. Primeiramente, realizou-se uma préamostragem, considerando-se a quantidade de árvores existentes em 5 quarteirões aleatoriamente escolhidos nas 10 áreas. Com estes dados, definiu-se o tamanho ideal da amostra para cada área, ou seja, o número de quarteirões necessário para fornecer dados com erro estatístico menor do que $15 \%$, através da fórmula $n=t^{2} \cdot N$. (cv) ${ }^{2} /(e d) \cdot N+t^{2} \cdot(c v)^{2}$, sendo $\mathbf{n}$ o número ideal de amostras, $\mathbf{N}$ o número total de quarteirões, $\mathbf{c v}$ o coeficiente de variação definido pela razão porcentual entre o desvio padrão e a média de árvores por quarteirão; ed erro desejável e $\mathbf{t}$ distribuição de student (tabela).

Parâmetros levantados: espécie, quantidade, estado físico das copas, altura, DAP. A identificação das espécies foi feita em campo, através de parâmetros dendrológicos primários (material fértil) e secundários (tronco, ritidoma, casca viva e morta, folhas, cheiros, exsudatos, raízes e arquitetura de copa). Das espécies menos conhecidas, foram colhidas amostras de partes férteis e herborizadas, para comparação com o acervo do herbário da 
UFAC. Também recorreu-se à literatura específica como Lorenzi (1998), (2004), Ribeiro (1999), Araújo (2000) e Souza (2005).

\section{RESULTADOS E DISCUSSÃO}

Um item muito importante na determinação da qualidade da arborização urbana é o elenco de suas espécies, considerando características individuais e do seu conjunto. Características individuais importantes, como origem, plasticidade ecológica, resistência ao ataque de pragas e doenças, características físicas da madeira, porte, arquitetura da copa, características estéticas, fenologia, cor das flores, componentes tóxicos ou alérgicos, características funcionais, dentre outras devem ser cuidadosamente observadas. A diversidade das espécies, bem como a freqüência da ocorrência dos indivíduos também é muito importante. Percebe-se, pela Tabela 1, uma quantidade de espécies abaixo do encontrado na maioria das cidades brasileiras. É importante também uma análise qualitativa e em um primeiro parâmetro, já se observa uma quantidade muito grande de espécies exóticas, totalizando 28, contra apenas 11 nativas. Sob o ponto de vista ecológico adaptativo e funcional, é tecnicamente recomendável o uso de espécies nativas da região trabalhada, principalmente para garantir relações ecológicas co-evolutivas e genéticas, de dispersão de propágulos (pólen e sementes) envolvendo fauna e flora dentro do ambiente urbano e também para conservação de material genético autóctone.

Quando se compara o total de espécies nas vias públicas da cidade de Rio Branco e o total de espécies florestais nativas encontradas por Araújo e Silva (2000) no Estado do Acre, totalizando 786 espécies, pode-se perceber que é uma quantidade muito pequena, apontando para o potencial existente para pesquisas na identificação de novas espécies florestais aptas ao meio urbano. 
TABELA 1 - Espécies e famílias botânicas encontradas nas ruas de Rio Branco - AC, segundo APG II (2003).

\begin{tabular}{|c|c|c|}
\hline NOME COMUM & NOME CIENTÍFICO & FAMÍLIA/ SUBFAMÍLIA \\
\hline Amora & Morus nigra L. & Moraceae \\
\hline Areca-bambu & Dypsis lutescens (H. Wendl.) Beentje e J. Dransf. & Arecaceae \\
\hline Baginha & Stryphnodendron guianensis ( Aubl ) Benth. & Mimosoideae \\
\hline Barriguda & Pseudobombax grandiflorum (Cav.) A. Robyns & Malvaceae \\
\hline Caju & Anacardium occidentale $\mathrm{L}$. & Anacardiaceae \\
\hline Carambola & Averrhoa carambola L. & Oxalidaceae \\
\hline Chapel-de-praia & Terminalia catappa L. & Combretaceae \\
\hline Coco & Cocos nucifera $\mathrm{L}$. & Arecaceae \\
\hline Espatodea & Spathodea campanulata P. Beauv. & Bignoniaceae \\
\hline Espirradeira & Nerium oleander $\mathrm{L}$. & Apocynaceae \\
\hline Falsa-murta & Murraya exótica L. & Rutaceae \\
\hline Fícus-benjamim & Ficus benjamim L. & Moraceae \\
\hline Flamboyant & Delonix regia (Boger ex Hook.) Raf. & Caesalpinioideae \\
\hline Goiaba & Psidium guayava $\mathrm{L}$. & Mirtaceae \\
\hline Graviola & Annona muricata Mill. & Annonaceae \\
\hline Hibisco & Hibiscus rosa sinensis L. & Malvaceae \\
\hline Ingá & Inga sp & Mimosoideae \\
\hline Ipê-amarelo & Tabebuia serratifolia (Vahl) Nich. & Bignoniaceae \\
\hline Ipê-de-jardim & Tecoma stans (L) Juss. ex Kunth & Bignoniaceae \\
\hline Jambo-branco & Mapronea guianensis Aubl. P. C. & Melastomataceae \\
\hline Jambo-vermelho & Syzigium malaccense (L.) Merr. E L. M. Perry & Mirtaceae \\
\hline Jambolão & Syzygium cumini (L.) Skeels & Mirtaceae \\
\hline Jaqueira & Artocarpus heterophyllus Lam. & Moraceae \\
\hline Jitó & Guarea sp & Meliaceae \\
\hline Lanterneira & Lophantera lactescens Ducke & Malpighiaceae \\
\hline Laranja & Citrus sp & Rutaceae \\
\hline Manga & Mangifera indica L. & Anacardiaceae \\
\hline Oiti & Licania tomentosa (Benth.) Fritsch. & Chrysobalanaceae \\
\hline Olho-de-pavão & Anadenanthera pavonina L. & Mimosoideae \\
\hline Pata-de-vaca & Bahuinia variegata $\mathrm{L}$. & Cercidae \\
\hline Pau-ferro & Caesalpinia ferrea Mart. & Caesalpinioideae \\
\hline Pingo-de-ouro & Duranta repens aurea $\mathrm{L}$. & Verbenaceae \\
\hline Pinha & Annona squamosa L. & Annonaceae \\
\hline Pinheiro & Pinus sp & Pinaceae \\
\hline Sibipiruna & Caesalpinia peltophoroides Benth. & Caesalpinioideae \\
\hline Sombreiro & Clitorea fairchildiana R. A. Howard & Papilionoideae \\
\hline Tamanqueira & Zanthoxyllum rhoifolium Lam. & Rutaceae \\
\hline Tamarindus & Tamarindus indica L. & Caesalpinioideae \\
\hline Umari & Paraqueiba sericea Tul. & Icacinaceae \\
\hline
\end{tabular}

Pode-se observar espécies tóxicas, como Spathodea campanulata e Nerium oleander. Desta última espécie, apenas uma folha pode causar intoxicação e morte (DL 50 
de $0,18 \mathrm{mg} / \mathrm{kg}$ de oleandrina - $18 \mathrm{~g}$ da planta pode matar um homem de $80 \mathrm{~kg}$ ) (PLANTAMED, 2008). Obviamente, espécies com princípios tóxicos e alérgicos devem ser evitadas em locais públicos.

São encontradas também 15 frutíferas, apontando para uma intervenção da população na escolha das espécies de forma espontânea, optando por espécies produtivas de frutos comestíveis. Espécies produtoras de pequenas frutas podem e devem ser utilizadas, principalmente visando a alimentação da avifauna. O que deve ser evitado é a utilização de espécies com frutos médios e grandes, que podem provocar acidentes e outros inconvenientes, como a manga e a jaca, sobre pessoas e veículos. Também frutos com pigmentos coloridos podem causar manchas na pintura dos veículos, principalmente os de cor clara, devendo ser evitados como o jambolão e o jambo vermelho (possuem grande concentração de antocianina).

Algumas espécies também devem ser observadas por possuírem alta capacidade de propagação e estabelecimento, constituindo-se perigosa planta invasora de áreas abertas, podendo interferir e mesmo prejudicar ou impedir os processos de sucessão vegetal natural, como é o caso da Tecoma instans, espécie exótica.

O quadro da diversidade de espécies e freqüências observadas nas vias públicas de Rio Branco, conforme Figura 2, reflete o encontrado em outras cidades brasileiras. Observamos poucas espécies com elevado número de indivíduos e muitas espécies com poucos indivíduos, concentrando-se $62 \%$ do total de indivíduos em apenas 5 espécies, expondo uma grande fragilidade ecológica. 


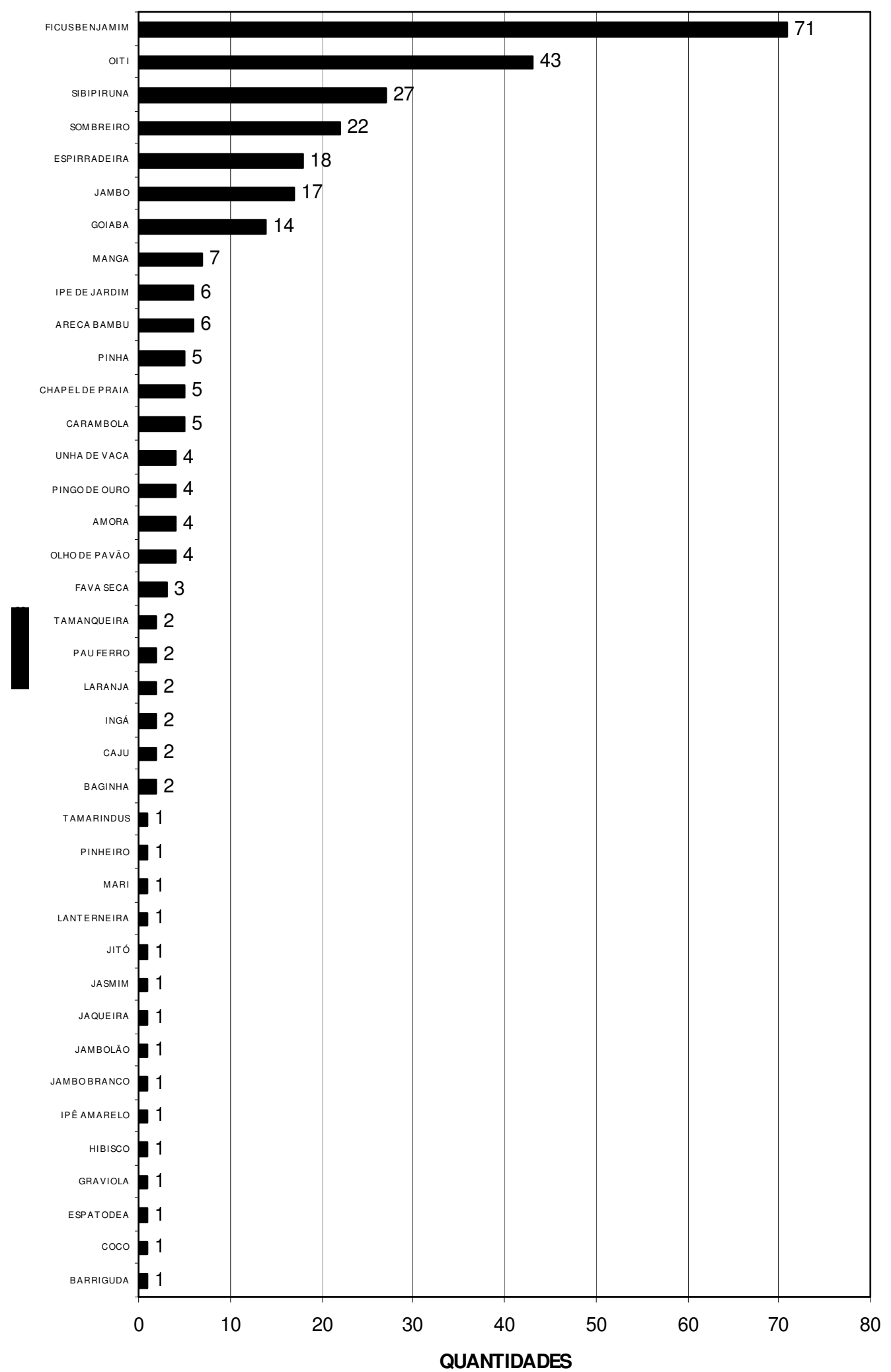

FIGURA 2 - Freqüência das espécies arbóreas encontradas nas vias públicas de Rio Branco-AC. 
No nordeste brasileiro, Dantas e Souza (2004) estudando a arborização de Campina Grande na Paraíba encontraram 132 espécies, com a predominância de 15, destacando-se dentre elas as de maior freqüência a Cássia-amarela - Senna siamea, (17,3\%), Algaroba Prosopis juliflora (14,0\%), Sombreiro - Cliptoria fairchildiana $(10,5 \%)$, Castanhola Terminalia catappa (8,4\%), Mata-fome - Pithecolobium dulcis (5,5\%), Cacau-bravo - Pachira aquatica Aubl (4,4\%), Ipê-amarelo - Tabebuia sp (3,9\%), Flamboyant - Delonix Regia (3,5\%), Oitizeiro - Licania tomentosa (3,2\%), Figo-benjamina - Ficus benjamina (2,6\%), Oliveira Syzigium jambolana (2,3\%), Palmeira-imperial - Roystonea oleracea (2,0\%), Aroeira-dapraia - Schinus terebinthifolius (1,9\%), Espatódia - Spathodea campanulata $(1,8 \%)$ e Cássiabrasil Adenanthera pavonina (1,4\%). Apesar de existirem muitas espécies, aparecem em freqüências desproporcionais, onde poucas são observadas em altas quantidades e a maioria, com pouquíssimos indivíduos.

Estudando a situação da arborização viária dos Bairros Antônio Zanaga I e II em Americana - SP, Silva (2005) encontrou 2.551 árvores plantadas, sendo a maioria de espécies exóticas, distribuídas entre 76 espécies diferentes, com maiores freqüências da Falsa-murta - Murraya exótica com 18,42\%, Ligustro - Ligustrum lucidum com 16,50\% e Oiti - Licania tomentosa com 12,47\%, acima de $10 \%$.

Nas ruas da orla de Santos, SP, em levantamento da arborização viária para sua Dissertação de Mestrado, Meneghetti (2003) encontrou entre as 10 espécies mais frequentes, o Ingá - Inga laurino (25,91\%), Saboneteira - Sapindus saponaria (20,23\%), Chapel-de-praia - Terminalia catapa (13,39\%), Ficus - Ficus microcarpa (4,75\%), Flamboyant - Delonix regia (3,97\%), Resedá - Lagestroemia indica (3,97\%), Guanandi Calophyllum brasiliensis (3,89\%), Ipê-verde - Cybistax antysiphilitica (2,26\%), Sombreiro Clitoria fairchildiana (2,02\%) e Murta - Murala paniculata (2,02\%). Citando MOLL ${ }^{3}$ (1987), que afirma ser a freqüência ideal máxima de $10 \%$ por espécie, não recomenda o plantio das três espécies acima deste, como forma de correção do problema.

Em Campos de Jordão, estância turística do Estado de São Paulo tendo como característica principal as baixas temperaturas promovidas pela sua elevada altitude, atraindo visitantes em busca de ambientes e hábitos próximos aos das cidades de clima temperado, Andrade (2002), encontrou 32 espécies arbóreas. Afirma em sua Dissertação de Mestrado que mais da metade da cidade é arborizada com plátanos $(53,7 \%)$, espécie típica de clima temperado, sendo a árvore símbolo dos Canadenses. Os Liquidâmbares somam $34,1 \%$. Os outros $12,2 \%$ correspondem às outras espécies. Também se pode observar a

\footnotetext{
${ }^{3}$ MOLL, G. Improving the health of the urban forest. American Forests, v. 93, n. 11/12, p. 61-64, nov/dez 1987.
} 
mesma situação das outras cidades, embora com espécies diferentes: um número reduzido de espécies dominantes, com freqüências muito altas, ficando o restante das espécies com pouquíssimos indivíduos.

Estudando a arborização do Bairro Benfica na cidade do Rio de Janeiro, Couto (2006) encontrou 1.231 árvores (66,80\%) e 367 mudas (19,91\%) distribuídas por 80 espécies diferentes. As espécies com maior freqüência relativa foram a Amendoeira Terminalia catapa, (18,5\%), Munguba (15,5\%), Oiti (10,3\%), Cássia siamea (3,8\%), Pata-devaca $(4,4 \%)$, Mangueira $(3,6 \%)$, Coqueiro $(2,4 \%)$, Fícus beijamina $(3,4 \%)$, Falso ébano Albizia lebeck (2,0\%) e Flamboyant (2,3\%). Como se observa, a população inventariada encontra-se dominada por três espécies (amendoeira, munguba e oiti) que somam mais de $50 \%$ de toda a população com DAP acima de $5 \mathrm{~cm}$.

Em Uberlândia - MG, Silva (2002) mostrou que o levantamento por eles desenvolvido contemplou um total de 728 indivíduos distribuídos em 53 espécies e 28 famílias botânicas. As cinco espécies que apresentaram maior freqüência foram: Michelia champaca $(16,4 \%)$, Bauhinia variegata (12,4\%), Ligustrum japonicum (11,7\%), Murraya exotica $(10,7 \%)$ e Caesalpinia peltophoroides (9,7\%). Estas representaram aproximadamente $61,0 \%$ da população amostrada. Afirma que é comum na arborização urbana, que poucas espécies representem a maior parte da população, mesmo não sendo uma situação desejável sob vários aspectos.

No Estado do Paraná, Milano (1987), desenvolvendo trabalho sobre o planejamento da arborização de Curitiba, cita que $92 \%$ da população de árvores de rua é representada por 18 espécies, de um total de 93 inventariadas, sendo a mais comum o Lagerstroemia indica (24\%), seguida pelo Tabebuia roseoalba (8,9\%) e Tabebuia chrysotricha (7,7\%). Concluiu que para melhorar a qualidade da arborização viária daquele município, existia a necessidade de adequada seleção de espécies, dentre outras medidas.

Em Manaus, Costa (1993) também encontrou situação semelhante, inventariando as árvores das calçadas para sua dissertação de mestrado. A espécie Licania tomentosa (Benth.) Fritsch aparece com freqüência $29,42 \%$, seguida pela Terminalia catappa Linn. com $17,87 \%$, totalizando $47,3 \%$. As 12 espécies mais freqüentes somaram 87,4\%, apontando para um replanejamento da arborização viária daquela cidade da região norte do país.

O que se percebe no Brasil todo é uma grande necessidade de se planejar a arborização urbana, principalmente no quesito diversidade de espécies e freqüência dos indivíduos dentro de cada espécie, objetivando uma distribuição mais uniforme dos indivíduos dentro de cada uma delas, para garantir uma menor vulnerabilidade ambiental. Muitas espécies se repetem no país todo, não se considerando as particularidades climáticas e ambientais, como nas regiões frias e secas do Sul do País, regiões quentes e 
secas do Nordeste, regiões quentes e úmidas do Norte e regiões mesófilas do sudeste e centro-oeste brasileiros, que possuem espécies endêmicas com grande potencial ornamental.

Deve-se, portanto, investir em pesquisas sobre novas espécies, principalmente nativas, visando aumentar a diversidade das mesmas no ambiente urbano, buscando, nelas características positivas, não somente de parâmetros estéticos, mas funcionais. Em cada um dos biomas brasileiros existe uma grande diversidade de espécies florestais e dentre elas, devemos procurar indivíduos com características que possibilitem seu cultivo no meio urbano, permitindo assim o usufruto de seus serviços ambientais.

Também não devemos nos prender a índices elaborados para condições ecológicas e de biodiversidade de países de clima temperado, onde as espécies arbóreas são muito menos diversificadas. Uma referência a ser discutida, poderia ser sobre um valor mínimo relativo à biodiversidade encontrada em cada região do país, como, por exemplo, $10 \%$ das espécies arbóreas nativas, considerando os vários estágios sucessionais. Assim sendo, em Rio Branco, trabalharíamos com um horizonte de 78 espécies, ao invés de 39.

Os aspectos quantitativos também são importantes, para avaliar a efetividade de uma arborização urbana. Considera-se como referencial ideal o índice de 100 árvores por quilômetro de calçada, ou seja, uma árvore na frente de cada residência, estimando-se a testada média de terrenos urbanos no Brasil como sendo de $10 \mathrm{~m}$. Em Rio Branco, encontramos 4,57 árvores por quilômetro de calçada, ou seja, de cada 100 residências, menos de 5 tem uma árvore em sua calçada. Em Águas de São Pedro-SP, Bortoleto (2004) observou 130 indivíduos por quilômetro de calçada. Em Manaus-AM observou-se 20 árvores por quilômetro de calçada (Costa e Higuchi, 1999). Em Campos de Jordão-SP, Andrade (2002) constatou 17 árvores por quilômetro de calçada, e já em Assis-SP, Rossato et al. (2008) encontraram 37,87 árvores por quilômetro de calçada. Constata-se que o índice de árvores por quilometro de calçada em Rio Branco é um dos menores do país.

Dados fornecidos por eletricistas da ELETROACRE indicam a existência de 150.000 consumidores de energia no município de Rio Branco, o que nos leva a estimar que existam aproximadamente 6.855 árvores em suas calçadas.

Outro parâmetro muito importante para se aferir a qualidade da arborização viária, é o estado físico das copas.

As calçadas pavimentadas representam para as árvores, o local mais estressante do sítio urbano, estando sujeitas às condições mais adversas. A impermeabilização das calçadas dificulta as trocas de água e gases do solo com a atmosfera e vice versa, elimina a ciclagem de nutrientes, expõe as árvores aos mais diversos danos físicos, deste acidentes 
com pedestres e veículos, até o manejo inadequado, principalmente provocado por podas incorretas.

As árvores viárias de Rio Branco encontram-se sob condições semelhantes. A Figura 3 exibe o estado físico das copas das árvores, por bairro. Pode-se perceber que a condição de copa normal é predominante, exceto na região central. Isto pode ser explicado pelo fato da arborização nesta região da cidade ser mais antiga, com copas maiores, disputando espaço físico com os outros equipamentos, principalmente, com as redes aéreas de distribuição de energia elétrica, estando mais expostas e a mais tempo, à podas drásticas. Nos outros bairros, pela arborização ser mais recente, os danos são menores, mas pode-se observar o avanço dos mesmos, pela significativa porcentagem de árvores com copas medianamente deformadas.

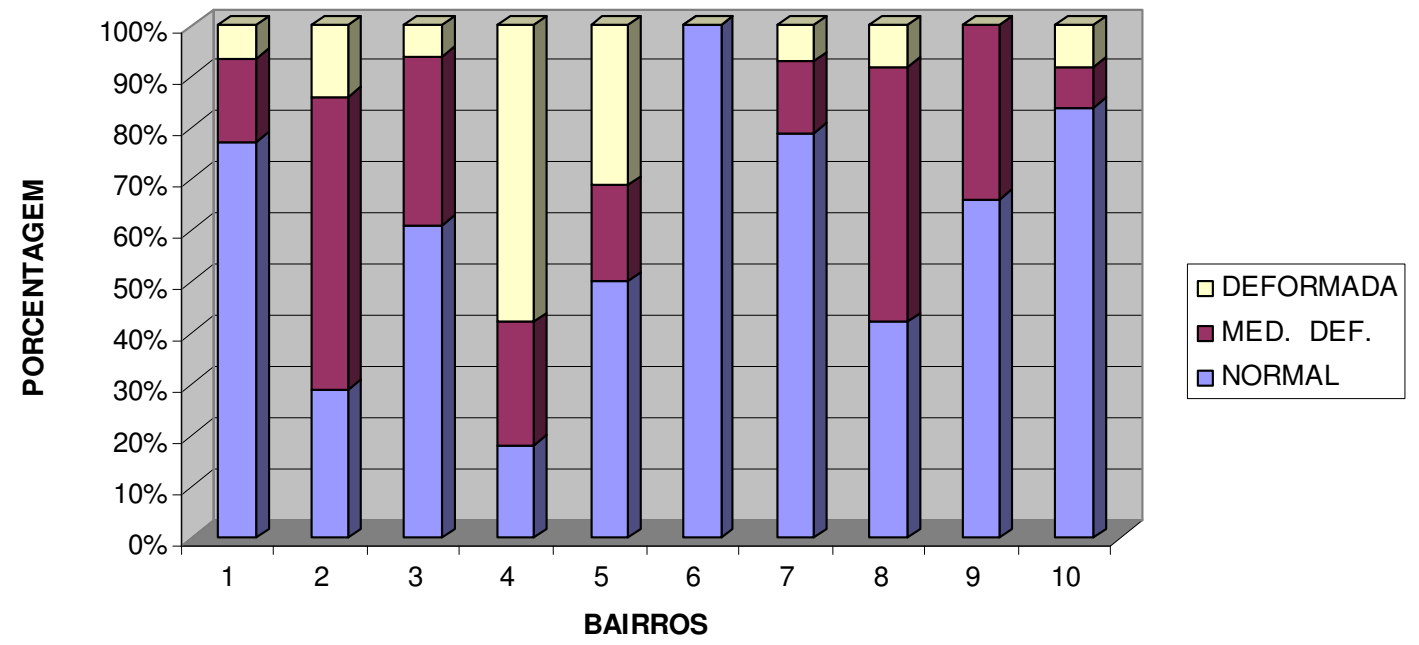

FIGURA 3 - Estado físico das copas das árvores.

1- Conj. Universitário; 2 - Tancredo Neves ;3 - Floresta; 4 - Centro; 5 - Rui Lino, Distrito Industrial, Mocinha; 6 - Conquista, Sta Quiteria, Ivonete; 7 - Estação Experimental; 8 Procom-Solar; 9 - Tucumã; 10 - Boa União e Glória.

Em Nova Iguaçu-RJ, em pesquisa nos bairros Rancho Novo e Centro, Rocha et al. (2004) observaram que cerca de $34 \%$ dos indivíduos com altura inferior a $6,0 \mathrm{~m}$ apresentaram DAP superior a $10 \mathrm{~cm}$, indicando plantas na fase adulta que sofreram intervenções de poda, caracterizando a redução do seu porte. Em Santa Maria - RS, no Conjunto Habitacional Tancredo Neves, Teixeira (1999) detectou que $46 \%$ dos danos ocasionados às árvores foi por meio da poda. Costa e Higuchi (1999) constataram em Manaus que $15 \%$ das árvores apresentaram copa boa, $65 \%$ regular e $19 \%$ ruim.

As medidas recomendadas para reverter esta tendência seriam a implementação de um programa de educação ambiental permanente, junto à comunidade, enfatizando os benefícios da arborização no meio urbano, a implementação de normas legais balizadoras do manejo adequado da arborização e a ministração de cursos técnicos de poda aos 
funcionários da prefeitura, de empresas terceirizadas prestadoras de serviços de poda, como também de funcionários das empresas concessionárias dos serviços de distribuição de energia elétrica e corpo de bombeiros.

\section{CONCLUSÕES}

A arborização viária do município de Rio Branco-AC é insatisfatória, tanto sob aspectos quantitativos quanto qualitativos.

Verifica-se a necessidade de se desenvolver um planejamento integrado do verde público ao planejamento urbano como um todo, entre Governo do Estado, Prefeitura, concessionária de distribuição de energia elétrica, universidades e a comunidade.

No aspecto quantitativo, verifica-se a necessidade urgente de implementação de plantios, através da adoção de um programa permanente de arborização urbana.

A diversidade das espécies necessita ser ampliada, o que aponta para o desenvolvimento de pesquisas para identificação de novas espécies, principalmente nativas, frente ao potencial de biodiversidade Amazônico, bem como de técnicas de manejo para sua efetivação.

Também se faz necessário o desenvolvimento de programa de educação ambiental, visando sensibilizar a população sobre a importância da arborização urbana, principalmente pelos seus serviços ambientais, para envolvê-la efetivamente no processo, garantindo não só a redução da depredação, mas o seu pleno desenvolvimento.

Um programa de treinamento dos podadores, tanto da prefeitura e das empresas prestadoras de serviços terceirizados como também dos eletricistas das concessionárias dos serviços de distribuição de energia elétrica seria de fundamental importância para um bom manejo da arborização.

\section{REFERENCIAS BIBLIOGRAFICAS}

ACRE. Governo do Estado do Acre. Programa Estadual de Zoneamento EcológicoEconômico do Estado do Acre. Zoneamento Ecológico-Econômico do Acre Fase II: documento Síntese - Escala 1:250.000. Rio Branco: SEMA, 2006. 356 p.

AGENCIA ACRE. Disponível em < WWW.agencia.ac.gov.br $>$ consultado em 10/03/2009. 
ANDRADE, T. O. Inventário e análise da arborização viária da estância turística de Campos do Jordão, SP. Dissertação ( Mestrado em Agronomia - Fitotecnica) Escola Superior de Agricultura Luiz de Queiroz - ESALQ USP, Piracicaba, SP, 2002.

APG [= Angiosperm Phylogeny Group] II. 2003. An update of the Angiosperm Phylogeny Group classification for the orders and families of flowering plants: APG II. In: Bot. J. Linnean Soc. 141: 399-436.

ARAÚJO, H. J.B. e SILVA, I. G. Lista de espécies florestais do Acre:ocorrência com base em inventários florestais. Rio Branco: EMBRAPA Acre, 2000, 77 p.

COSTA, L. A. Análise e avaliação do manejo da arborização urbana pública da cidade de Manaus. Dissertação (Mestrado em Biologia Tropical e Recursos Naturais) - Instituto Nacional de Pesquisas da Amazônia, Manaus, 1993.

COSTA, L. A.; HIGUCHI, A. Arborização de ruas de Manaus: avaliação qualitativa e quantitativa. Revista Árvore, Viçosa, v. 23, n. 2, p. 213-221, 1999.

COUTO,C.S. Inventário e diagnóstico da arborização urbana do bairro de Benfica, município do Rio de Janeiro, RJ. 2006. 44 f. Monografia (Graduação em Engenharia Florestal) - Instituto de Florestas, Universidade Federal Rural do Rio de Janeiro, Seropédica, 2006.

COUTO, H.T.Z.; RACHID, C. Estudo da eficiência de dois métodos de amostragem de árvores de rua na cidade de São Carlos - SP. Scientia Forestalis, Piracicaba, n. 56, p. 5968, 1999.

DANTAS, I. C; SOUZA, C. M. C. Arborização urbana na cidade de Campina Grande - PB: Inventário e suas espécies. Revista de Biologia e Ciências da Terra ,v. 4, n. 2, 2004.

ELETROPAULO. Guia de planejamento e manejo da arborização urbana. São Paulo: Eletropaulo: Cesp: CPFL, 1995. 40 p.

LORENZI, H. Árvores Brasileiras: manual de identificação e cultivo de plantas arbóreas nativas do Brasil. 2 Ed. Nova Odessa, SP: Editora Plantarum, 1998. 352 p. 
LORENZI, H. Palmeiras Brasileiras e Exóticas cultivadas. Nova Odessa, S.P: Editora Plantarum, 2004. 416 p. il.

MACEDO, S. S. Quadro do paisagismo no Brasil. São Paulo: QUAPÁ, 1999, 143 p.

MENEGHETTI, G. I. P. Estudo de dois métodos de amostragem para inventário da arborização de ruas dos bairros da orla marítima do município de Santos, SP. Dissertação (Mestrado em Recursos Florestais) - Departamento de Ciências Florestais, Escola Superior de Agricultura Luiz de Queiroz - ESALQ USP, Piracicaba, SP, 2003.

MILANO, M. S. Arborização das ruas de Curitiba, PR: uma análise qualitativa. In: Encontro Nacional sobre Arborização Urbana, 1985, Porto Alegre. Anais. Porto Alegre: Secretaria Municipal de Meio Ambiente, 1985. p 83-86.

MILANO, M. S. O planejamento da arborização, as necessidades de manejo e tratamentos culturais das árvores de ruas de Curitiba, PR. Floresta, v.17, n.1/2, p.15-21, jun./dez.1987.

MILLER, R. W. Urban Forestry: planning and managing urban grenspaces. Upper Saddle River, New Jersey, USA: Prentice Hall, 1996, 502 p.

PLANTAMED.

Disponível

em

$<$ http://www.plantamed.com.br/plantaservas/especies/Nerium oleander.htm > consultado em 10-05-08.

RIBEIRO, J.E.L.S et al. Flora da Reserva Ducke: Guia de identificação das plantas vasculares de um floresta de terra-firme na Amazônia Central. Manaus: INPA,1999. 816 p. il..

ROCHA, R. T; LELES, P. S. S.; OLIVEIRA NETO, S. N. Arborização de vias púbicas em Nova Iguaçu, RJ: o caso dos bairros Rancho Novo e Centro. Revista Árvore, Viçosa, MG, vol.28 no.4, julho/agosto, 2004.

ROSSATTO D. R.; TSUBOY, M. S. F.; FREI, F. Arborização Urbana na cidade de Assis-SP: uma abordagem quantitativa. Revista da Sociedade Brasileira de Arborização Urbana, Piracicaba, v.3, n.3, set. 2008, p. 1-16. 
SILVA, E. M. Estudo da arborização urbana do bairro Mansour, na cidade de UberlândiaMG. Caminhos de Geografia, Uberlândia, MG, v. 3, n. 5., p. 73-83, 2002.

SILVA, L. F. Situação da arborização viária e proposta de espécies para os bairros Antônio Zanaga I e II, da cidade de Americana/SP. Dissertação (Mestrado em Fitotecnia) - Escola Superior de Agricultura Luiz de Queiroz - ESALQ-USP, Piracicaba, SP, 2005.

SOUZA, V. C. Botânica sistemática: guia ilustrado para identificação das famílias de angiospermas da flora brasileira, baseado em APG II. Nova Odessa, SP : Instituto Plantarum, 2005, 640 p il..

TEIXEIRA, I. F. Análise qualitativa da arborização de ruas do Conjunto Habitacional Tancredo Neves, Santa Maria - RS. Ciência Florestal, Santa Maria, RS. v. 9, n. 2, 1999. 